\title{
Use Intention of Aggregator Medical Mobile Apps' (M-apps) and Revealing Reasons for Non-Use ${ }^{1}$ \\ Dr. Sally Raouf Garas
}

\author{
Lecturer of Marketing \\ Faculty of Financial and Administrative Sciences \\ Pharos University in Alexandria \\ sally.raouf@pua.edu.eg
}

\begin{abstract}
The current study has two main objectives. The first, is to examine the impact of perceived ease of use, usefulness, risk and product involvement on intention to use aggregator medical mobile apps. The second objective is to reveal factors which might make some healthcare consumers not use aggregator medical mobile apps. Thus, a single cross sectional descriptive research was employed, and questionnaires were used to gather data from 111 app users over two months (March and April 2021) from Cairo, Giza and Alexandria. Multiple regression was used to test the research hypotheses. Results indicate that perceived usefulness, product involvement and perceived ease of use have significant positive impacts on intention to use aggregator medical mobile apps, while perceived risk has no significant impact on intention. Moreover, the responses of nonusers shed light on reasons which discourage them from using this type of medical mobile apps.
\end{abstract}

Keywords: Mobile marketing, mobile apps, medical mobile apps, technology acceptance model (TAM).

\section{1- Introduction}

The healthcare market in Egypt is a large stable market that attracts many private investors; with developments in Information Communication Technology (ICT), new services are offered to the healthcare market, among which is eHealth (Badran, 2019). eHealth is the use of ICT in health products and processes, integrated with mobile healthcare delivery systems to improve the health of citizens, efficiency

\footnotetext{
${ }^{1}$ Received in 23 June 2021, accepted in 27 August 2021.
} 
of providers and facilitates institution-to-institution transmission of data and/or communication between patients and health professionals. eHealth has various applications, three of the most known are Electronic Health Records (EHR), Personal Health Records (PHR) and mobile health applications. Electronic Health Records (EHR) enable patients to disclose their medical history to their healthcare providers who in turn access and share it among the authorized healthcare stakeholders to provide more personalized care to their patients. While, Personal Health Records (PHR) enable patients to have access to their health information, by which they can maintain and manage it in a private secure environment. PHR can be linked to EHR or can standalone; Finally, mobile healthcare (medical) applications (m-apps) are software programs downloaded to run on computers or mobile devices to achieve a healthcare purpose (Zhang and Koch, 2015; Badran, 2019, Mansour, 2017; Elsafty et al., 2020).

Generally, eHealth has numerous benefits for healthcare consumers, providers, and governments (Brohi et al., 2019). More specifically, for healthcare consumers, it provides patients with reminders for their medication and medical examination appointments thus increases their awareness in case of chronic diseases, it also provides them with professional and social support and helps them during emergencies. For healthcare providers, eHealth applications enable them to access patients' data and the updated medical records and hence increases the accuracy of treatments based on evidence and reduces human effort and costs of redundancies. For governments, eHealth enhances a country's healthcare system and overcomes the shortage of skilled healthcare personnel in rural and poor areas, resulting in high life expectancy, quality of life, and shorter treatment periods (Badran, 2019).

Hence, driven by the promising benefits of eHealth and its nature as an emerging area of research, and taking into consideration Egypt's 2030 sustainable development vision of increasing ICT penetration and digital transformation of the healthcare sector, as well as starting to enact the new healthcare law; several studies have been conducted in Egypt to measure the intention of Egyptians to adopt stand-alone PHR (Elsafty et al., 2020), EHR (Badran, 2019) and medical m-apps 
(Mansour, 2017). These studies used the Technology Acceptance Model (TAM) or the Unified Theory of Acceptance and Use of technology (UTAUT) as their theoretical foundation.

However, the impact of product involvement of eHealth consumers on their intention to use eHealth applications have not been measured yet. Despite that healthcare is a service characterized by high credence qualities, and difficulty, on the consumer's part, of evaluating the actual provided service; and thus, it is considered a high involvement product category, where consumers exert more effort in gathering information and evaluating possible choices before purchase. Additionally, providers can manage their relationship with consumers by reducing perceived risks and facilitating information search (Mortimer and Pressey, 2013).

Moreover, the current research aims to measure the intention/adoption rate of aggregator medical m-apps. Especially that there is a proliferation of aggregator healthcare (medical) (m-apps) (e.g. Vezeeta, Tabibi, Doctor online, and Elbalto) providing consumers with features as searching for a physician/medical service, reading patients' reviews, booking for having a healthcare services either physically, virtually or consulting over the phone. Thus, those apps tend to facilitate the whole decision process and the pre-decision phase in particular. Hence it is important to compare the intention/adoption rate of aggregator medical m-apps to intention/adoption rates of other eHealth applications (e.g. Mansour, 2017; Elsafty et al., 2020).

Consequently, the current study is an extended application of TAM, the theoretical robust and sound model. By which perceived risk and product involvement as potential predictors of intention to use aggregator medical $\mathrm{m}$-apps are also examined. Moreover, the current research aims to provide insights of the reasons which discourage nonusers from adopting these m-apps. Consequently, results can benefit m-app developers, providers and marketers to meet consumers' needs with adjusted app features, increasing downloads and eventually benefiting all healthcare stakeholders. Especially that, the private sector, represented by aggregator medical m-apps developers and 
healthcare service provider's platforms can be incorporated into the Egyptian Healthcare system through EHR.

The remainder of the paper includes a review of relevant literature and development of research hypotheses, followed by the proposed model, methodology, data analysis and findings and finally the discussion, implications and limitations.

\section{2- Literature Review}

\section{2-1 Background: Mobile Apps (m-apps)}

Generally, m-apps are one of the mobile marketing tools which have lately gained prominence as essential digital tools for businesses and consumers alike. Yet, before proceeding in describing m-apps, there is a need to clarify the scope of mobile marketing and its relationship with mobile commerce. Firstly, mobile commerce is any monetary-related transaction through an internet-enabled mobile device (Shukla and Sharma, 2018; Roy and Moorthi, 2017). While, mobile marketing is a set of practices that enable a business to interactively communicate and engage with its target audience through any mobile device or network (Mobile Marketing Association, 2009). Clearly, mobile marketing is an integral part of mobile commerce.

Traditionally, businesses used push promotional mobile marketing strategies, which were not preferred by most consumers. Lately, with the developments in mobile technology, businesses shifted to pull promotion, using a number of tools among which m-apps are one of the most important (Leppaniemi and Karjaluoto, 2008; Kushwaha and Agrawal, 2016; Roy and Moorthi, 2017). Apparently, m-apps are software designed to perform specific tasks on personal mobile devices (as smartphones and tablets) and can also run-on computers (Tang, 2019), they are similar to a retailers' virtual store providing consumers with a number of benefits as security, less clutter, more interactivity and customized features (Nair and Bhattacharyya, 2019).

The marketing literature includes a number of classifications and types of m-apps. The main types are category m-apps (apps are classified according to the category they belong to, as shopping, healthcare, games...etc), branded m-apps (apps display the brand's identity and 
support its main business) and aggregator (third party) m-apps (are digital platforms which provide products from a number of providers who outsource ordering, logistics and payment systems to a third party). Moreover, m-apps can be free apps, by which users do not have to pay for downloading, or can be paid which require users to pay the price of the app before downloading it (Hew, et al., 2015; Tsalgatidou and Pitoura, 2001; Stocchi et al., 2019; Nair and Bhattacharyya, 2019; Tang, 2019).

Recently, and more specifically, healthcare m-apps (sometimes called mHealth apps) have attracted the interest of researchers and practitioners from various disciplines, representing a relatively new area (Li and Chang, 2020) that has implications on the micro (patients and healthcare providers) and on the macro level (healthcare industry and the economy) (Mansour, 2017).

In fact, many researchers attempt to classify healthcare m-apps directed to consumers. For example, Kao and Liebovitz (2017) classify them into six types, which are: wellness-management apps (helps users to maintain a healthy lifestyle as fitness apps, sleep and meditation apps), disease-management apps (are designed for chronic disease management as diabetics), self-diagnosis apps (provide initial selfdiagnosis and checking without a need for a medical visit), medicationreminder apps and electronic-patient-portal apps (allow patients to access part of their medical records and lab results, upcoming appointments and allow them to communicate with their doctors), and physical medical and rehabilitation apps (provide tools to monitor the impact of home-exercise programs and educational materials on patients). Likewise, DeCelles-Zwernman (2014); cited in Mansour (2017) indicate that generally there are ten types of healthcare apps, but four of them target patients; those are: reminder-apps, healthy-life apps, general-facility information apps (give patients general info about facilities) and patient portal apps (give patients access to their electronic medical records and provide easier communications with their doctors). While, Dawson et al. (2019) classify healthcare m-apps into two categories: health and wellness apps (aimed to help consumers to have a healthy lifestyle) and medical apps (used to diagnose and track diseases and facilitate communications between the provider and 
the app user). Medical m-apps include apps to locate nearby doctors or hospitals using GPS and features to book doctors' appointments through either aggregator or the hospital's mobile app. Medical m-apps is the type of app that is understudy.

Despite the large number and types of healthcare m-apps, they differ in their capabilities and consumers' adoption rate. Actually, reminder apps, wellness-management apps and general facility information apps are the most healthcare apps downloaded by Egyptian users (Mansour, 2017).

\section{2-2 Technology Acceptance Model (TAM) and Hypotheses Development}

Technology Acceptance Model (TAM) (Davis, 1989) is among the leading models which has high explanatory power for users' acceptance and adoption of new technology across various contexts and countries (Holmes et al., 2014; Cho and Sagynoy, 2015). It also has high expansion tolerance (Vahdat et al., 2020; Gao and Bai, 2014; Marangunic and Granic, 2015). The main model posits that perceived ease of use and perceived usefulness predict intention to use a new technology which in turn predicts actual usage. TAM has undergone a number of modifications to increase its predictive validity (Marangunic and Granic, 2015; Roy and Moorthi, 2017); and still has tolerance and flexibility for further expansion (Vahdat et al., 2020; Shukla and Sharma, 2018).

Given that downloading and using medical m-apps usually involves giving permission to the app to utilize some personal information concerning users' health issues. Hence, users may have some privacy concerns when using these types of apps. Moreover, healthcare services are characterized by its credence qualities. That is, it is difficult to evaluate the service even after buying. Thus, healthcare consumers (patients) are usually highly involved when confronted by a healthcare service purchase situation.

Consequently, the current research expands the basic TAM by studying the impact of perceived risk and product involvement on intention to use aggregator medical m-apps. 


\section{2-2-1 Antecedents to m-apps Use Intention}

\section{2-2-1-1 Perceived Ease of Use}

Generally, a new technology will have no value if not adopted by its target users (Li and Chang, 2020). Clearly, it is adopted if an individual perceives its benefits (Vahdat et al., 2020). Perceived ease of use of the process and perceived usefulness of the new technology (Cho and Sagynoy, 2015) are among the perceived benefits of a new technology. More precisely, perceived ease of use is the extent a person believes that using a new technology will be easy and will not require additional effort (Marangunic and Granic, 2015; Zhang et al., 2018). Previous research demonstrates that perceived ease of use increases intention to adopt/use a given technology (e.g., Davis, 1989; Gao and Bai, 2014; Ozturk, 2016; Roy and Moorthi, 2017; Chakraborty, 2020). More specifically, intention to use eHealth applications. For example, Mansour (2017) assert that almost 70\% of the sample indicate that medical m-apps are easy to use. Elsafty et al. (2020) confirms this result, by indicating that it significantly increases intention to use standalone ePHR. Likewise, Badran (2019) points out that effort expectancy significantly impacts intention to use EHR Therefore, H1 is proposed as:

H1: Perceived ease of use has a positive impact on intention to use aggregator medical m-apps

\section{2-2-1-2 Perceived Usefulness}

Perceived usefulness is the degree a person believes that a new technology will facilitate performing certain tasks and provide better benefits than current choices (Marangunic and Granic, 2015; Zhang et al., 2018). Hence, this construct is related to the outcome of the technology. In the context of online shopping, perceived usefulness can be obtaining more product information, better accessibility, speed, and convenient purchases (Cho and Sagynoy, 2015). Previous findings indicate that perceived usefulness significantly influences users' intentions to use m-apps in various contexts. Such as, grocery shopping m-apps in India (Shukla and Sharma, 2018), mobile learning apps in Pakistan (Bakhsh et al., 2017), dietary and fitness apps in Tiwan (Chen 
and Lin, 2018) and healthcare m-app in India (Chakraborty, 2020). Moreover, in Egypt, researchers confirm that healthcare consumers perceive usefulness of various eHealth applications. Precisely, Mansour (2017) indicates that all respondents confirm that they consider using medical m-apps as useful. Moreover, Elsafty et al. (2020) report that perceived ease of use significantly increase intention to use standalone ePHR. Likewise, Badran (2019) reports the same significant impact of performance expectancy on intention to adopt EHR. Hence, $\mathbf{H 2}$ is stated as follows:

H2: Perceived usefulness has positive impact on intention to use aggregator medical m-apps

\section{2-2-1-3 Perceived Risk}

As mentioned earlier, healthcare services are characterized by having high credence qualities where consumers cannot judge the quality of services, with certainty, even after purchase and consumption. Thus, consumers tend to perceive high risks before buying (Mitra et al., 1999; Girard and Dion, 2010; Mazaheri et al., 2012; Mortimer and Pressey, 2013).

Additionally, the use of mobile commerce involves a number of risks concerning the safety and privacy of users' information (Chakraborty, 2020). In fact, marketers are able to collect information about users during their online shopping, when visiting websites, downloading $\mathrm{m}$ apps or even using social media channels. Obviously, this information is collected by placing tracking software on the users' devices; hence tracing users' online behavior and collecting, aggregating and analyzing users' demographics and behavioral information which different organizations can then use to send personalized message that meet consumers' needs and preferences (Roy and Moorthi, 2017). Furthermore, with regard to medical m-apps, the issue of privacy and security of information relating the patient's data saved on apps' servers, such as location, contact information, diagnoses and medical history; as well as the issue of others having access to the users' personal information stored on the app in case of losing their phones, raises the concerns of many medical app users (Mansour, 2017). 
Previous research findings show that perceived risk significantly reduces intention to adopt mobile commerce (Chung and Holdsworth, 2012; Ozturk, 2016; Kalinic et al., 2019). Furthermore, it significantly reduces intention to adopt eHealth applications as stand-alone ePHR (Elsafty et al., 2020). While privacy concerns play an important role in adopting EHR (Badran, 2019). Additionally, increased protection concerns significantly impacts intention to adopt healthcare m-apps (Chakraborty, 2019). Accordingly, H3 is stated as:

H3: Perceive risk has a negative impact on intention to use aggregator medical m-apps

\section{2-2-1-4 Product Involvement}

The marketing literature classifies products according to consumers' needs, the difficulty of evaluating a product's attributes before purchase and the degree of a product's personal relevance to a consumer.

More specifically, since consumers are motivated by three types of needs: utilitarian (e.g., efficiency), self-esteem (self-respect and the respect of others) and hedonic needs (e.g., enjoyment, entertainment and social interaction). Thus, the same concept is used to classify products (Stewart et al., 2019). That is to say, products can be classified according to the main type of benefit they deliver to consumers. Therefore, utilitarian products mainly fulfill utilitarian or functional needs, status-related products are products that mainly satisfy selfesteem needs while hedonic products are products that mainly satisfy hedonic and emotional needs (Mittal and Lee, 1989; Stewart et al., 2019).

Additionally, products can be classified according to the level of information asymmetry or the degree it is possible for consumers to evaluate the product before purchase. Accordingly, products high in search qualities are easy to evaluate before purchase. While, products high in experience qualities are difficult to evaluate before consumption as they require consumers to try them before buying to be sure of the level of quality. While products high in credence qualities are difficult to evaluate, with certainty, before and after consumption (Mazaheri et al., 2012; Mortimer and Pressey, 2013). Hence, consumers preference to shop online for credence products are less than their preference to shop 
online for experience and search products, as it is difficult to obtain product attribute information for credence products (Korgaonkar et al., 2006). Consequently, credence products are characterized by being high involvement products. Classifying products according to their degree of relevance to a consumer into high/low involvement products is the third product classification.

Involvement construct originated from psychology and has been used in marketing since 1966 especially in consumer behavior and advertising studies (Morosan and Defranco, 2016). It is defined as the perceived personal relevance of an object to a consumer resulting in an interest in that object (Mittal and Lee, 1989; O'Cass, 1989; Stewart et al., 2019). Involvement can also be defined as the extent to which a consumer perceives a certain object as a central part of his/her life. Consequently, the construct is oriented towards a certain context/focal stimulus which may be a product, purchase situation, consumption and/or advertising (marketing communications); resulting in four forms of involvement which constitute a consumer involvement profile (O'Cass, 1989). While, Mittal and Lee (1989) clarify that there are two forms of involvement: which are product and purchase (branddecision) involvement. Product involvement is the interest in and importance of a product category to a person. While purchase (branddecision) involvement is the interest in and importance of making a careful rather than a causal (impulsive) brand choice. Moreover, involvement can be enduring which is an ongoing concern with a product category across different purchase situations based on centrally held values by the consumer. And it can be situational which is interest in a product in specific situations and thus varies across different situations (Mazaheri et al., 2012; Sarkar and Sarkar, 2019).

Generally, the degree of personal relevance of a product to a consumer is the result of interaction between the individual's needs, interests and values (Menidjel et al., 2020) and the frequency (importance) of the purchase and the level of perceived risks associated with buying the product (Friedmann and Lowengart, 2019; Stewart et al., 2019). Accordingly, the individual then is motivated to engage in information processing of the product of interest either extensively or lightly, persistently or temporary (Ferreira and Coelho, 2015). 
It has been proved that the level of involvement is related to information search (Mortimer and Pressey, 2013). That is, when consumers are making a certain purchase, the degree to which they are motivated to process information regarding the different product options depends on the personal relevance of the product to them (Ferreira and Coelho, 2015; Bian and Moutinto, 2011; Mou et al., 2020). Accordingly, some product categories are associated with being more relevant and receive more interest from consumers when buying them than other product categories. More specifically, high involvement products are highly relevant to consumers and result in more information processing to reach a decision choice than low involvement products (Stewart et al., 2019; Mou et al., 2020).

To sum up, and drawing upon Elaboration Likelihood Model (ELM), when buying high involvement products (more relevant products to consumers), consumers are likely to follow a central route for decision making, exerting more effort in processing information and evaluating alternatives (Mou et al., 2020; Friedmann and Lowengart, 2019). Since aggregator medical $\mathrm{m}$-apps are apps for utilitarian credence products (healthcare or medical services), thus, consumers are likely to be highly involved when taking the decision. At the same time, aggregator medical m-apps make product information available and facilitate the search and pre-purchase evaluation among various product/service choices, by reducing information asymmetry for healthcare consumers. Hence, consumers will be more inclined to use aggregator medical mapps to have more product information.

Although product involvement has not been studied in the context of medical eHealth applications yet. However, previous research show that it significantly increases intention to use m-apps in general. For example, Morosan and DeFranco (2016) reveal that involvement significantly increases hotel guests' intention to use hotel m-apps. Likewise, Kang et al. (2015) report that involvement significantly influences intention to download Location Based Services (LBS) retail apps. while Sarkar and Sarkar (2019) point out that category app involvement has a positive significant impact on the loyalty towards the app category (continence intention to use service-based apps). 
Therefore, the following is proposed regarding users' healthcare (medical care) involvement:

H4: Product involvement has a positive impact on intention to use aggregator medical m-apps

\section{3- The Research Model}

The proposed research model is illustrated in figure (1).

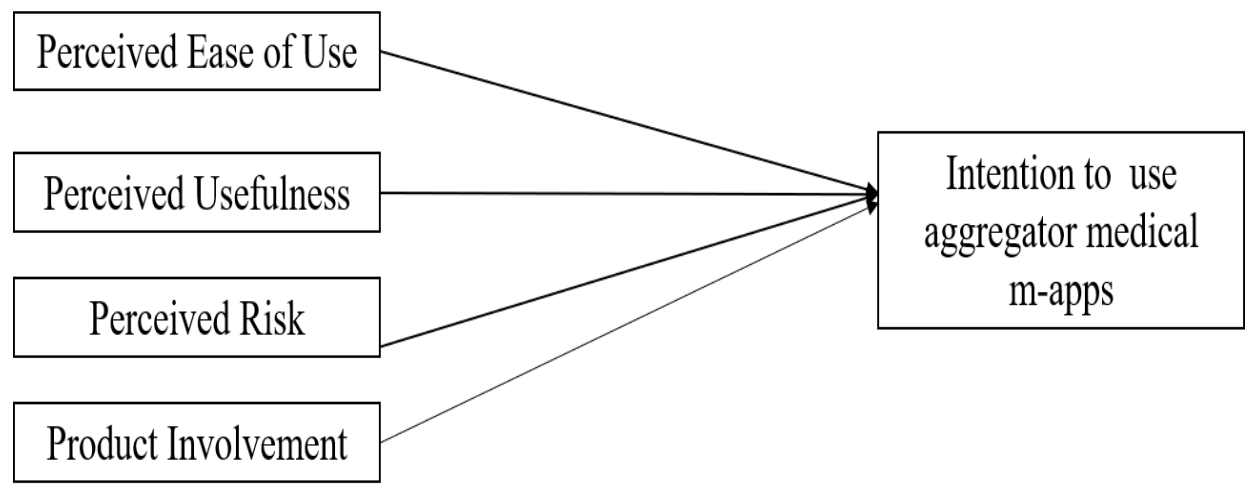

Figure 1: Proposed Research Model

\section{4- Study Context}

The study is concerned with measuring the intention of aggregator medical m-apps (as, Vezeeta, Tabibi, and Elbalto) users to use them, and finding out reasons which make some healthcare consumers non-users of these apps. Given the documented low adoption/intention to use rate of various eHealth applications in Egypt (Elsafty et al., 2020; Badran, 2019; Mansour, 2017), as well as, the low-user engagement and retention of medical m-apps, globally (Li and Chang, 2020), thus the researcher selected free aggregator medical $\mathrm{m}$-apps which have been introduced to the Egyptian market before 2020, in order to have a reasonable user response rate.

\section{5- Research Methodology}

\section{5-1 Population and Sample}

The population of the study includes all aggregator medical m-app users in Egypt during the period from 1/3/2021 till 30/4/2021. Hence, the sampling unit is aggregator medical $\mathrm{m}$-app users in, because it was 
perceived that app users are familiar with at least one of the aggregator medical apps and thus can answer the perceived ease of use and perceived usefulness question items based on actual experience. Thus, the population of the study includes all aggregator medical m-app users in Egypt.

According to Enterprise Press, the number of mobile subscribers in Egypt in March 2020 was 96.42 million, which is more than $90 \%$ of the total Egyptian population. Moreover, in January 2021, there were 59.19 million internet users in Egypt (Dataportal.com). Consequently, since not all mobile and internet subscribers use aggregator medical m-apps. Thus, obtaining a sampling frame for the population of the study was not possible. And thus, a snowball sample was used to reach the target respondents.; and a required sample size of $384^{1}$ was targeted.

\section{5-2 Data Collection}

Data was gathered from respondents in Alexandria, Cairo and Giza using a questionnaire, during March and April 2021. The questionnaire started by an introduction of the purpose of the research and explaining the meaning of aggregator medical m-apps, then a screening question, asking respondents whether they use any of the aggregator medical mapps (pictures of apps' icons were associated with the question). Respondents who answered yes were the target sample, and thus were asked to continue the survey. While respondents who answered no were asked to answer the demographic section and an open-end question of the reasons which make them not use aggregator medical m-apps.

The questionnaire was developed in English, then translated to Arabic and back translated to English. Then, it was checked by two university professors (an assistant professor of marketing and a lecturer of management) and pilot tested among 20 respondents for testing its clarity and their comprehension of the question items.

1 The required sample size $n=z^{2} s^{2} / e^{2}$ (Rose et al., 2015). At a 95\% confidence level, $\mathrm{z}$ is \pm 1.96 ; the acceptable level of error (e) is $5 \%$. The sample standard deviation (s) was 0.5 (based on a pilot study of 20 respondents). Therefore, the required sample size $=384$ 


\section{5-3 Measures}

The questionnaire items were based on previously validated scales. More specifically, perceived risk was adapted from Bauer et al. (2005) and Kalinic et al. (2020), perceived ease of use and perceived usefulness were adopted from Davis (1989). Intention to use aggregator medical m-apps was adapted from Kalinic et al. (2020). These variables were measured using a five-point Likert scale. While product involvement was measured using Zaickowsky's (1985) involvement seven-point Semantic Differential scale.

\section{Data Analysis and Findings}

\subsection{Respondents' Characteristics}

Out of the 384 targeted, 322 questionnaires were received, however, 36 were discarded because of missing values. Thus, out of the 286 valid responses, 111 were users of aggregator medical m-apps (were asked to complete the whole questionnaire) and 175 were non-users (were asked to complete the demographic section and an open-end question regarding reasons of not using medical m-apps). Yielding an overall response rate of $74.5 \%$. The description of users and non-users are shown in Table (1). In this regard, users represent $38.8 \%$ of the valid responses while non-users represent $61.2 \%$. This usage rate is similar to usage rates reported by eHealth applications research conducted in Egypt. More specifically, Mansour (2017) reports that $40 \%$ of the sample are medical m-apps' users. While, Elsafty et al. (2020) point out that $11 \%$ of the sample were users of standalone ePHR. Moreover, Chakraborty (2020) indicates that $7.86 \%$ of the sample were using healthcare mobile apps in India.

Table 1: Descriptive Analysis of Respondents

\begin{tabular}{|c|c|c|c|c|c|}
\hline \multirow{2}{*}{ Demographics } & \multirow{2}{*}{ Category } & \multicolumn{2}{|c|}{ Users= 111 } & \multicolumn{2}{c|}{ Non-users= 175 } \\
\cline { 3 - 6 } & & Frequency & Percent & Frequency & Percent \\
\hline \multirow{2}{*}{ Gender } & Male & 62 & 55.86 & 116 & 66.29 \\
\cline { 2 - 6 } & Female & 49 & 44.14 & 59 & 33.71 \\
\hline \multirow{3}{*}{ Age } & From 20- less than 30 & 31 & 27.93 & 121 & 69.14 \\
\cline { 2 - 6 } & 30 less than 40 & 28 & 25.23 & 18 & 10.29 \\
\cline { 2 - 6 } & 40 less than 50 & 36 & 32.43 & 25 & 14.29 \\
\hline
\end{tabular}




\begin{tabular}{|c|c|c|c|c|c|}
\hline \multirow{4}{*}{ Demographics } & \multirow{2}{*}{ Category } & \multicolumn{2}{|c|}{ Users $=111$} & \multicolumn{2}{|c|}{ Non-users $=175$} \\
\hline & & Frequency & Percent & Frequency & Percent \\
\hline & 50 less than 60 & 14 & 12.61 & 9 & 5.14 \\
\hline & 60 and more & 2 & 1.80 & 2 & 1.14 \\
\hline \multirow{2}{*}{ Marital Status } & Not Married & 35 & 31.53 & 123 & 70.29 \\
\hline & Married & 76 & 68.47 & 52 & 29.71 \\
\hline \multirow{3}{*}{$\begin{array}{c}\text { Last } \\
\text { Education } \\
\text { Degree }\end{array}$} & $\begin{array}{l}\text { High school and } \\
\text { Equivalent }\end{array}$ & 16 & 14.41 & 40 & 22.86 \\
\hline & University & 29 & 26.13 & 62 & 48.00 \\
\hline & Graduate Studies & 66 & 59.46 & 73 & 29.14 \\
\hline \multirow{3}{*}{$\begin{array}{c}\text { Employment } \\
\text { Status }\end{array}$} & Employed & 90 & 81.08 & 106 & 60.57 \\
\hline & Do not work & 3 & 2.70 & 24 & 13.71 \\
\hline & Student & 18 & 16.22 & 45 & 25.71 \\
\hline
\end{tabular}

\section{6-2 Preliminary Analysis}

\section{6-2-1 Reliability}

Composite reliability (CR) and Cronbach's alpha were used to assess the consistency and stability of measures. As shown in Table (2), CR of all research variables met the recommended cutoff point for establishing CR which is 0.70 (Malhotra, 2010), its values ranged between 0.840 (perceived risk) and 0.975 (intention to use aggregator medical mapps). Moreover, Cronbach's alpha ranged between 0.716 (perceived risk) and 0.983 (product involvement).

Table 2: Reliability of Research Variables

\begin{tabular}{|l|c|c||c|}
\hline \multicolumn{1}{|c|}{ Measures } & $\begin{array}{c}\text { Number } \\
\text { of items }\end{array}$ & $\begin{array}{c}\text { Cronbach's } \\
\text { Alpha }\end{array}$ & $\begin{array}{c}\text { Composite } \\
\text { reliability } \\
\text { CR }\end{array}$ \\
\hline Perceived ease of use & 3 & 0.897 & 0.936 \\
\hline Perceived usefulness & 6 & 0.933 & 0.948 \\
\hline Perceive risk & 4 & 0.716 & 0.840 \\
\hline Product involvement & 20 & 0.983 & 0.943 \\
\hline Intention to use aggregator medical m-apps & 3 & 0.911 & 0.975 \\
\hline
\end{tabular}

4-2-2 Validity of the research variables

Convergent validity was measured by examining the minimum requirements for factor loadings and the Average Variance Extracted (AVE) of the variables. Table (3) shows that all factor loadings met the 
cutoff point of 0.40 . Moreover, the AVE of all items by their respective constructs were greater than the variance unexplained (that is AVE> 0.50) (Fornell and Larcker, 1981), as shown in Table (4). Hence convergent validity was established.

Table 3: Loadings of Items

\begin{tabular}{|c|c|c|}
\hline Variable & Item & Loading \\
\hline \multirow{3}{*}{$\begin{array}{l}\text { Perceived Ease of } \\
\text { Use }\end{array}$} & $\begin{array}{l}\text { Learning to use aggregator medical m-apps is easy } \\
\text { for me }\end{array}$ & .892 \\
\hline & $\begin{array}{l}\text { it is easy to find a needed specialized physician } \\
\text { when I use aggregator medical m-apps }\end{array}$ & .917 \\
\hline & I find aggregator medical m-apps easy to use & .924 \\
\hline \multirow{6}{*}{$\begin{array}{l}\text { Perceive } \\
\text { Usefulness }\end{array}$} & $\begin{array}{l}\text { Using aggregator medical m-apps help me find a } \\
\text { specialized physician and book an appointment } \\
\text { more quickly. }\end{array}$ & .881 \\
\hline & $\begin{array}{l}\text { Using aggregator medical m-apps help me find a } \\
\text { specialized physician and book an appointment with } \\
\text { less effort }\end{array}$ & .881 \\
\hline & $\begin{array}{l}\text { aggregator medical m-apps help me compare } \\
\text { examination /consultation fees of a number of } \\
\text { physicians and healthcare providers* }\end{array}$ & .749 \\
\hline & $\begin{array}{l}\text { I can read useful patients' reviews when using } \\
\text { aggregator medical m-apps* }\end{array}$ & .891 \\
\hline & $\begin{array}{l}\text { I find aggregator medical m-apps useful when I need } \\
\text { a doctor/medical service }\end{array}$ & .875 \\
\hline & $\begin{array}{l}\text { Aggregator medical m-apps makes finding a } \\
\text { specialized doctor/medical service easier }\end{array}$ & .922 \\
\hline \multirow{4}{*}{ Perceived Risk } & $\begin{array}{l}\text { Other people can know information about my online } \\
\text { transactions if I use aggregator medical m-apps }\end{array}$ & .843 \\
\hline & $\begin{array}{l}\text { There is a risk of personal data being misused when } \\
\text { downloading aggregator medial } \mathrm{m} \text {-apps }\end{array}$ & .924 \\
\hline & $\begin{array}{l}\text { Using aggregator medical m-apps to book an } \\
\text { appointment with a physician/ have a medical } \\
\text { service is a risky choice }\end{array}$ & .924 \\
\hline & $\begin{array}{l}\text { Strangers could easily access my personal } \\
\text { information when I download aggregator medical } \\
\text { m-apps }\end{array}$ & .892 \\
\hline \multirow{5}{*}{$\begin{array}{l}\text { Product } \\
\text { Involvement }\end{array}$} & unimportant/important & .813 \\
\hline & of no concern/of concern to me & .875 \\
\hline & irrelevant/relevant & .831 \\
\hline & means nothing to me/means a lot to me & .901 \\
\hline & useless/useful & .867 \\
\hline
\end{tabular}




\begin{tabular}{|c|c|c|}
\hline Variable & Item & Loading \\
\hline & valuable/worthless & .874 \\
\hline & trivial/fundamental & .860 \\
\hline & not beneficial/beneficial & .901 \\
\hline & doesn't matter to me/matters to me & .920 \\
\hline & uninterested/interested & .917 \\
\hline & insignificant/significant & .898 \\
\hline & superfluous/vital & .882 \\
\hline & boring/interesting & .821 \\
\hline & unexciting/exiting & .912 \\
\hline & unappealing/appealing & .885 \\
\hline & mundane/fascinating & .796 \\
\hline & non-essential/essential & .877 \\
\hline & undesirable/desirable & .778 \\
\hline & unwanted/wanted & .853 \\
\hline & not needed/needed & .914 \\
\hline \multirow{3}{*}{$\begin{array}{l}\text { Intention to use } \\
\text { the m-app }\end{array}$} & $\begin{array}{l}\text { I am likely to use aggregator medical m-apps in the } \\
\text { future }\end{array}$ & .912 \\
\hline & $\begin{array}{l}\text { Given the opportunity, I will use aggregator medical } \\
\text { m-apps for booking a medical service }\end{array}$ & .930 \\
\hline & $\begin{array}{l}\text { Most probably, I will use aggregator medical m-apps } \\
\text { in the future }\end{array}$ & .919 \\
\hline
\end{tabular}

* Developed by the researcher

Table 4: Average Variance Extracted (AVE)

\begin{tabular}{|l|c||}
\hline \multicolumn{1}{|c|}{ Measures } & $\begin{array}{c}\text { Average Variance } \\
\text { Extracted (AVE) }\end{array}$ \\
\hline Perceived ease of use & 0.830 \\
\hline Perceived usefulness & 0.753 \\
\hline Perceived Risk & 0.569 \\
\hline Product Involvement & 0.848 \\
\hline Intention to use aggregator medical m-apps & 0.752 \\
\hline
\end{tabular}

\section{6-2-3 Confirmatory Factor Analysis}

Then, Confirmatory Factor Analysis (CFA) was conducted to test the validity of the measurement model. As illustrated in Table (5), results show an adequate goodness of fit values of the model. More precisely, GFI, NFI and CFI values range between 0.883 and 0.986 which is between the adequate range ( 0 and 1 ). Moreover, the value of DMIM/DF is between 1.853 and 2.135 which is less than the cutoff point of 3 . Furthermore, the value of RMSEA is between 0.05 and 0.06 also less 
than 0.08 (Browne and Cudeck, 1992; cited in Morosan and DeFranco, 2016).

Table 5: Confirmatory Factor Analysis (CFA)

\begin{tabular}{|l|c|c|c|c|c|}
\hline \multirow{2}{*}{ Measures } & \multicolumn{5}{|c|}{ indicators } \\
\cline { 2 - 6 } & GFI & NFI & CFI & CMIN /DF & RMSEA \\
\hline Perceived ease of use & 0.986 & 0.965 & 0.972 & 1.985 & 0.05 \\
\hline Perceived usefulness & 0.952 & 0.939 & 0.953 & 2.118 & 0.05 \\
\hline Perceive risk & 0.913 & 0.870 & 0.883 & 1.987 & 0.06 \\
\hline Product involvement & 0.943 & 0.915 & 0.931 & 2.135 & 0.06 \\
\hline $\begin{array}{l}\text { Intention to use } \\
\begin{array}{l}\text { aggregator medical m- } \\
\text { apps }\end{array}\end{array}$ & 0.959 & 0.932 & .936 & 1.835 & 0.05 \\
\hline
\end{tabular}

\section{6-3 Hypotheses Testing}

To measure the relationships between the independent variables (perceived ease of use, perceived usefulness, perceived risk and product involvement) and the dependent variable (intention to use aggregator medical m-apps), multiple regression was conducted, as shown in Table (6).

Table 6: Multiple Regression Analysis

\begin{tabular}{|c|c|c|c|c|c|c|}
\hline $\begin{array}{c}\text { Dependent } \\
\text { Variable }\end{array}$ & $\begin{array}{c}\text { Independent } \\
\text { Variables }\end{array}$ & B & T-Value & Sig. & Decision & $\begin{array}{c}\text { Rating } \\
\text { List }\end{array}$ \\
\hline \multirow{4}{*}{ 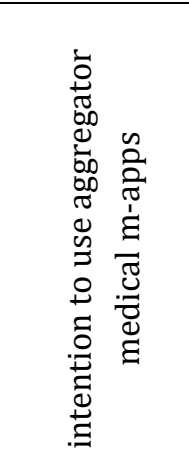 } & $\begin{array}{c}\text { Perceived ease } \\
\text { of use }\end{array}$ & 0.176 & 2.135 & 0.022 & Supported & 3 \\
\hline & $\begin{array}{c}\text { Perceived } \\
\text { usefulness }\end{array}$ & 0.521 & 4.636 & 0.000 & Supported & 1 \\
\hline & Perceive risk & -0.069 & 1.320 & 0.190 & $\begin{array}{c}\text { Not } \\
\text { supported }\end{array}$ & - \\
\hline & $\begin{array}{c}\text { Product } \\
\text { involvement }\end{array}$ & 0.231 & 3.546 & 0.001 & Supported & 2 \\
\hline $\begin{array}{l}\mathrm{R}=0.840 \\
\mathrm{R}^{2}=0.705 \\
\text { Adjusted } \mathrm{R}^{2}=\end{array}$ & .693 & Sig $=0.000$ & $\begin{array}{l}=51.727 \\
0\end{array}$ & & & \\
\hline
\end{tabular}

As shown in Table (6), except for the insignificant impact of perceived risk, all independent variables significantly increase intention to use aggregator medical m-apps. More specifically, perceived usefulness (B $=0.521, \mathrm{p}<0.05$ ) has the greatest impact on intention to use aggregator 
medical m-apps, followed by product involvement $(B=0.231, p<0.05)$, then perceived ease of use $(B=0.176, p<0.05)$. While perceived risk $(B=$ $-0.069, \mathrm{p}>-0.05$ ) has no significant impact on intention to use medical m-apps. Thus, H1, H2 and H4 are supported, while H3 is not supported. Additionally, adjusted $\mathrm{R}^{2}$ of the model is 0.693 indicating that perceived usefulness, product involvement and perceived ease of use explain $69.3 \%$ of intention to use aggregator medical m-apps.

\section{7- Revealing Reasons of Not Using Aggregator Medical m- apps}

Non-users report a number of reasons which discourage them from using aggregator medical m-apps. The main themes of their responses, as well as some supporting quotations together with their demographics, are illustrated as follows:

\section{7-1 There is no perceived need for aggregator medical m- apps. Non-users prefer the traditional way of going to physicians they already know or going to doctors recommended personally to them by their acquaintances.}

\section{Supporting quotations}

"I don't use medical m-apps because my dad is a doctor so I already have the names and addresses of good doctors in various specialties" [A single female student, age from 20-less than 30 years old].

"If I feel ill, I go to a doctor who I personally know" [A single male employee, age from 20 - less than 30 years old, holding a university degree].

"I don't use them because my husband is a doctor" [A married employed female, age from 31-40 years old, holding a university degree].

"I don't use medical m-apps as I depend on my relatives' personal experience" [A single employed female, holding a post-graduate degree, age from 30 -less than 40 years old].

"Because I am old fashion" [A single male student age from 20-less than 30 years old]. 
"When I don't feel well, I call my friends who are doctors" [A married university graduate female who does not work and aged from 40- less than 50 years old].

"I have never thought of using them, I don't need them" [A single female student, age from 21-30 years old].

"I prefer calling a doctor when needed" [A single university graduate male employee, and aged from 30 -less than 40 years old].

\section{7-2 Lack of trust in medical m-apps}

\section{Some supporting quotations}

"I do not trust medical m-apps" [A married university graduate employed female, age from 50 to less than 60 years old].

"You have to have a credit card and specify personal information; thus, I prefer to go to a hospital directly" [A single male, who does not work and his age is from 20 -less than 30 years old].

\section{7-3 Have the will, but have not tried them yet}

\section{Supporting quotations}

"it's not that I don't want to, it's just I've never had the chance to give them a shot, maybe I'll do at some time" [A single university graduate male employee, age from 20-less than 30 years old].

"I haven't had the opportunity or the idea to deal with medical apps yet, however I'd like to in the future" [A single female student, age from 20less than 30 years old].

\section{7-4 Perceived Difficulty to Use}

\section{Supporting quotation}

"Because I do not know how to use them" [A single female student, age from 20 to less than 30 years old].

\section{8- Discussion and Implications}

The first objective of the study was to measure factors which motivate Egyptian healthcare consumers to use aggregator medical m-apps. 
To achieve this objective, the study extended TAM and, in this regard, perceived ease of use and perceived usefulness were tested together with perceived risk and product involvement. In this regard, findings indicate that:

Factors which motivate consumers to use aggregator medical m-apps are perceived usefulness, followed by product involvement, and finally perceived ease of use. However, perceived risk has no significant impact on use intention. A possible explanation is that aggregator medical mapp users are either unaware of the potential threats to their personal and private medical information or have trust in aggregator medical mapps they use. Moreover, findings regarding perceived usefulness and perceived ease of use are consistent with previous eHealth application studies conducted in Egypt (Badran, 2019; Elsafty et al., 2020), in fact the latter study shows that perceived usefulness has the greatest impact on intention to use standalone ePHR, followed by perceived ease of use, then perceived risk. Current research findings are also partly consistent with Chakraborty (2020) who indicates that perceived usefulness significantly impacts intention to use healthcare m-apps in India, while ease of use has no impact. Likewise, Yuan et al. (2015) find that performance expectancy significantly impacts intention to use health and fitness m-app in USA, while effort expectancy has no effect. These results imply that perceived usefulness of medical m-app can be considered as more important to users than perceived ease of use and perceived risk.

Although the impact of product involvement on intention to use aggregator medical $\mathrm{m}$-apps has not been tested before, current findings show that it has a significant positive impact on users' intention to use these types of medical apps. A result which is consistent with results of previous m-app studies in different contexts; as hotel m-apps (Morosan and DeFranco, 2016) and LBS retail m-apps (Kang et al., 2015).

Based on the mentioned research findings, several implications are proposed for parities involved in eHealth in Egypt, more specifically, the Egyptian Ministry of Health, aggregator medical app developers, healthcare providers and marketers: 
First, the Egyptian Ministry of Health has a crucial role in managing the healthcare digital transformation and needs to work with various healthcare provides, web/app developers and marketers to coordinate efforts and integrate various sources of healthcare consumers' data (from various eHealth applications, and platforms) into a secure confidential and comprehensive source (national HER). This source can ensure that data can be shared and retrieved only by authorized users across all eHealth applications and platforms; it also enables the healthcare consumer to have one integrated medical profile. This national HER is likely to benefit all stakeholders of the healthcare industry and increase perceived usefulness of m-apps.

Second, medical m-app developers can add more useful functional (utilitarian) features to their aggregator medical m-apps, and enhance users' app engagement through enriching the users' experience with the m-app. As a result, the high impact of product involvement levels on use intention can be sustained. In this regard, apps can include and/or send, important healthcare tips and easily-understood educational health information, reminders or alerts of check-up dates, follow-ups and medication times. As well as, automatically updating users' medical records (profile) and allowing users to track their medical tests results; directly communicate with healthcare providers and enabling users to turn to social media communities, sponsored by the medical m-app healthcare provider, for virtual support. In addition to customized services and feedback.

Third, app developers need to make sure that medical m-apps are simply designed and user-friendly to attract the elderly segment as well.

Fourth, marketers should better communicate updated app features and benefits (e.g., new medical services provided, more locations covered by the m-app, new payment systems offered...etc) and clarify any misperception healthcare consumers might hold about their medical apps.

As for the second research objective which was to shed light on reasons which discourage healthcare consumers from using aggregator medical $\mathrm{m}$-apps, the following is noted: 
Although there is a proliferation of different types of free medical mapps available to the healthcare Egyptian market in general (e.g., those belonging to specific healthcare institutions as Cleopatra Hospital app, Alborglab app... etc) and aggregator medical m-apps in particular; and despite that the current questionnaire distributed included screenshots of aggregator medical apps' icons that have been introduced to the Egyptian market before 2020 (e.g. Vezeeta, Tabibi, Ember and Elbalto), aiming that respondents could have at least used one of them; Surprisingly, the adoption rate of aggregator medical m-apps is still low (38.8\% of the sample). But, is similar to rates reported by previous eHealth application studies conducted in Egypt (e.g., Elsafty et al., 2020; Mansour, 2017). And in other countries as India (e.g., Chakraborty, 2020). This low adoption rate is critical, especially that the Egyptian government is increasing its digital transformation investment in healthcare. Therefore, it is important to address factors which may discourage healthcare consumers from using medical m-apps. In this regard, reasons reported by non-users include preferring the traditional way of finding a healthcare provider and receiving the needed service, in this case non-users perceive no need for using medical m-apps. Others do not feel confident in submitting their personal information to download and use these apps. Finally, others perceive difficulty in using aggregator medical m-apps. It is also worth noting that some respondents do not use aggregator medical m-apps because of having misperceptions. For example, some nonusers reported that they do not use aggregator medical m-apps because the need to have a credit card. However, e-payment does not apply for all aggregator medical apps. in fact, some apps allow users to book online and pay at the hospital/clinic.

To sum up, it is evident that there is a need for coordinated efforts among private and public healthcare providers and among marketing and $\mathrm{m}$-app developers to address the factors that might discourage healthcare consumers from using medical m-apps. More specifically, designing, managing and implementing nation-wide campaigns directed to educate consumers of the benefits of eHealth applications in general and reassure them of the security and confidentiality of their data is likely to encourage nonusers to adopt the most convenient 
medical app to them. At the same time, coordinated advertising campaigns of aggregator medical m-apps providers can also be implemented to increase healthcare consumers' awareness of the aggregator medical apps' features and the possible benefits of using such apps (e.g., convenience of booking and receiving the healthcare service, better communications with healthcare provides, reducing waiting time in clinics, providing patients with reminders of required tests).

Finally, it is worth noting that high adoption rates of eHealth applications are likely to supply good quality data which will enable machine learning to provide meaningful data patterns and build a reliable clinical decision support system, and thus will help healthcare providers find better treatments for diseases (Li and Chang, 2020) which eventually will enhance the entire healthcare system and enable it to reap the benefits of digital transformation of the healthcare sector.

\section{9- Limitations and Suggested Future Research}

First, the current research examines aggregator medical $\mathrm{m}$-apps in general, future studies can be applied on specific medical m-apps to have better perspective of consumers' perceptions of the medical app under study. Second, a quota sample can be used to have a better representation of the study population. Third, the impact of perceived risk on intention to use medical apps can be further examined by measuring the impact of different types of perceived risks (monetary, physical and psychological risks) on use intention. Fourth, longitudinal studies can be conducted to observe the change in users' behavior over time, moreover, continuance- expectation model can be used as a foundation to measure continuance intention to use medical m-apps. Finally, qualitative research can be conducted to have deeper and better understanding of nonusers' reasons for not adopting medical m-apps.

\section{References}

Badran, M. F. (2019). eHealth in Egypt: The demand-side perspective of implementing electronic health records. Telecommunications Policy, 43(6), 576-594. 
Bauer, H. H.; Reichardt, T.; Barnes, S. J., \& Marcus, M. N. (2005). Driving Consumer Acceptance of Location-Based Services in Mobile Applications: A Theoretical Framework and an Empirical Study. Journal of Electronic Commerce Research, 6(3), 181-192.

Brohi, P.; Khoumbati, K.-R., \& Nawaz Hakro, D. (2019). Barriers, Problems and Challenges in the Implementation of Mobile Healthcare Applications: A Systematic Literature Review.

Browne, M. W., \& Cudeck, R. (1992). Alternative ways of assessing model fit. Sociological methods \& research,21(2), 230-258. In: Morosan, C., \& DeFranco, A. (2016). Modeling guests' intentions to use mobile apps in hotels: The roles of personalization, privacy, and involvement. International Journal of Contemporary Hospitality Management, 28(9), 1968-1991.

Bian, X., \& Moutinho, L. (2011). The role of brand image, product involvement, and knowledge in explaining consumer purchase behaviour of counterfeits: Direct and indirect effects. European Journal of Marketing, 45(1), 191-216.

Chakraborty, D. (2020) Elements impacting the utilization expectation of various health care apps in India: a study conducted on smartphone users. Foresight, 22(3), 385-400.

Chen, M. F., \& Lin, N. P. (2018). Incorporation of health consciousness into the technology readiness and acceptance model to predict app download and usage intentions. Internet Research.

Cho, Y. C., \& Sagynov, E. (2015). Exploring factors that affect usefulness, ease of use, trust, and purchase intention in the online environment. International Journal of Management \& Information Systems (IJMIS), 19(1), 21-36.

Chung, K. C., \& Holdsworth, D. K. (2012). Culture and behavioural intent to adopt mobile commerce among the $\mathrm{Y}$ Generation: comparative analyses between Kazakhstan, Morocco and Singapore. Young Consumers. 
Davis, F. (1989). Perceived usefulness, perceived ease of use and user acceptance of information technology. MIS Quarterly, 13, 319340.

Dawson, R. M.; Felder, T. M.; Donevant, S. B.; McDonnell, K. K.; Card III, E. B.; King, C. C., \& Heiney, S. P. (2020). What makes a good health 'app'? Identifying the strengths and limitations of existing mobile application evaluation tools. Nursing inquiry,27(2), e12333.

Datareportal https://datareportal.com/reports/digital-2020-egypt [Accessed 27/11/2020]

DeCelles-Zwerneman, H. (2014) Everything you need to know about mobile health apps. In: Capterra Medical Software Blog. In: Mansour, E. (2017). Health Informatics: the ownership and use of mobile medical applications among Egyptian patients. Journal of Librarianship and Information Science. 49(3), 335355.

Elsafty, A.; Elbouseery, I. M., \& Shaarawy, A. (2020). Factors Affecting the Behavioral Intention to Use Standalone Electronic Personal Health Record Applications by Adults in Egypt. Business and Management Studies, 6(4), 14-35.

Enterprise

Press.

https://enterprise.press/stories/2020/08/25/egypts-mobilesubscriptions-inch-up-in-march-20737/ [Accessed 20/2/2021].

Ferreira, A. G., \& Coelho, F. J. (2015). Product involvement, price perceptions, and brand loyalty. Journal of Product and Brand Management, 24(4), 349-364.

Friedmann, E., \& Lowengart, O. (2019). Gender segmentation to increase brand preference? The role of product involvement. Journal of Product and Brand Management, 28(3), 408-420.

Fornell, C. and Larcker, D. F. (1981). Evaluating structural equation models with unobservable variables and measurement error. Journal of Marketing Research, 18 (1), 39-50. 
Gao, L., \& Bai, X. (2014). A unified perspective on the factors influencing consumer acceptance of internet of things technology. Asia Pacific Journal of Marketing and Logistics.

Girard, T., \& Dion, P. (2010). Validating the search, experience, and credence product classification framework. Journal of Business Research, 63(9-10), 1079-1087.

Kalinic, Z.; Marinkovic, V.; Molinillo, S., \& Liebana-Cabanillas, F. (2019). A multi-analytical approach to peer-to-peer mobile payment acceptance prediction.Journal of Retailing and Consumer Services, 49, 143-153.

Kao, C. K., \& Liebovitz, D. M. (2017). Consumer mobile health apps: current state, barriers, and future directions. $P M \& R, 9(5)$, S106S115.

Kang, J. Y. M.; Mun, J. M., \& Johnson, K. K. P. (2015). In-store mobile usage: Downloading and usage intention toward mobile location-based retail apps. Computers in Human Behavior, 46, 210-217.

Korgaonkar, P.; Silverblatt, R., \& Girard, T. (2006). Online retailing, product classifications, and consumer preferences. Internet Research.

Kushwaha, G. and Agrawal, S. (2016). The impact of mobile marketing initiatives on customers' attitudes and behavioural outcomes. Journal of Research in Interactive Marketing, 10 (3), 150-176.

Hew, J.; Lee, V.; Ooi, J.; Wei, J. (2015). What catalyses mobile apps usage intention: an empirical analysis. Industrial Management \& Data Systems. 115 (7), 1269-1291.

Holmes, A.; Byrne, A. and Rowley, J. (2014). Mobile shopping behavior: insights into attitudes, shopping process involvement and location. International Journal of Retail and Distribution Management, 42 (1), 25-39.

Li, J., \& Chang, X. (2020). Improving mobile health apps usage: a quantitative study on mPower data of Parkinson's disease. Information Technology \& People. 
Leppaniemi, M. and Karjaluoto, H. (2008). Mobile marketing: from marketing strategy to mobile marketing campaign implementation. International Journal of Mobile Marketing, 3(1), 50-61.

Marangunic, N. and Granic, A. (2015). Technology acceptance model: a literature review from 1986 to 2013. Univ Access Inf Soc, 14, 8195.

Malhotra, N. (2010). Marketing research: an applied orientation, (6th ed.). Global Edition, Prentice Hall, N.J.

Menidjel, C.; Benhabib, A.; Bilgihan, A., \& Madanoglu, M. (2020). Assessing the role of product category involvement and relationship proneness in the satisfaction-loyalty link in retailing. International Journal of Retail and Distribution Management, 48(2), 207-226.

Mansour, E. (2017). Health Informatics: the ownership and use of mobile medical applications among Egyptian patients. Journal of Librarianship and Information Science. 49(3), 335-355.

Mazaheri, E.; Richard, M. O., \& Laroche, M. (2012). The role of emotions in online consumer behavior: a comparison of search, experience, and credence services. Journal of Services Marketing.

Mitra, K.; Reiss, M. C., \& Capella, L. M. (1999). An examination of perceived risk, information search and behavioral intentions in search, experience and credence services. Journal of Services Marketing.

Mittal, B. and Lee, M. (1989). A causal model of consumer involvement. Journal of Economic Psychology, 10, 363-389.

Mobile Marketing Association (2009) http://www.mmaglobal.com/news/mma-updates-definitionmobile-marketing.[ Accessed 27/11/2020]

Morosan, C., \& DeFranco, A. (2016). Modeling guests' intentions to use mobile apps in hotels: The roles of personalization, privacy, and involvement. International Journal of Contemporary Hospitality Management, 28(9), 1968-1991. 
Mortimer, K., \& Pressey, A. (2013). Consumer information search and credence services: implications for service providers. Journal of Services Marketing.

Mou, J.; Zhu, W., \& Benyoucef, M. (2019). Impact of product description and involvement on purchase intention in cross-border ecommerce. Industrial Management \& Data Systems.

Nair, A. and Bhattacharyya, S. (2019). Is sustainability a motive to buy? An exploratory study in the context of mobile applications channel among young Indian consumers. Foresight, 12(2)177199.

Rose, S.; Spinks, N. and Canhoto, A. (2015). Management Research: applying the principles, Routledge, New York.

Roy, S. and Moorthi, Y. (2017). Technology readiness, perceived ubiquity and m-commerce adoption: the moderating role of privacy. Journal of Research in Interactive Marketing, 11(3),268295.

Sarkar, J. G., \& Sarkar, A. (2019). Young adult consumers' involvement in branded smartphone based service apps: Investigating the roles of relevant moderators. Information Technology and People, 32(6), 1608-1632. https://doi.org/10.1108/ITP-042017-0128

Shukla, A. and Sharma, S. (2018). Evaluating consumers' adoption of mobile technology for grocery shopping: an application of Technology Acceptance Model. Vision, 22(2), 185-198.

Stewart, K.; Kammer-Kerwick, M.; Auchter, A.; Koh, H.; Dunn, M.; Cimmingham, I. (2019). Examining digital video advertising (DVA) effectiveness: the role of product category, product involvement and device. European Journal of Marketing,53 (11),2495-2479.

Stocchi, L.; Michaelidou, N.; Micevski, M. (2019). Drivers and outcomes of branded mobile app usage intention. Journal of Product \& Brand Management 28(1), 28-49. 
Tang, A. (2019). A systematic literature review and analysis on mobile apps in m-commerce: implications for future research. Electronic Commerce Research and Applications, 37, 1-13.

Tsalgatidou, A., \& Pitoura, E. (2001). Business models and transactions in mobile electronic commerce: requirements and properties. Computer Networks, 37(2), 221-236.

O'Cass, A. (2000). An assessment of consumers product, purchase decision, advertising and consumption involvement in fashion clothing. Journal of Economic Psychology, 21, 545-576.

Ozturk, A. B.; Bilgihan, A.; Nusair, K., \& Okumus, F. (2016). What keeps the mobile hotel booking users loyal? Investigating the roles of self-efficacy, compatibility, perceived ease of use, and perceived convenience. International Journal of Information Management, 36(6), 1350-1359.

Vahdat, A.; Alizadeh, A.; Quach, S. and Hamelin, N. (2020). Would you like to shop via mobile app technology? The technology acceptance model, social factors and purchase intention. Australian Marketing Journal (in press).

Yuan, S.; Ma, W.; Kanthawala, S., \& Peng, W. (2015). Keep Using My Health Apps: Discover Users' Perception of Health and Fitness Apps with the UTAUT2 Model. Telemedicine and E-Health, 21(9), 735-741.

Zaichkowsky, J. (1985). Measuring the involvement construct. Journal of Consumer Research, 12, 341-352.

Zhang, T.; Lu, C. and Kizildag, M. (2018). Banking "on-the-go": examining consumers' adoption of mobile banking services. International Journal of Quality and Services Sciences, 10 (3),279-295.

Zhang, Y., \& Koch, S. (2015). Mobile health apps in Sweden: what do physicians recommend? In European Federation for Medical Informatics (EFMI), 793-797. 


\title{
النية لاستخدام تطبيقات الخدمات الطبية المجمعة للهاتف \\ واكتشاف أسباب علم الاستخدام
}

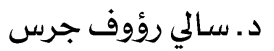

ملخص البحث باللغة العربية

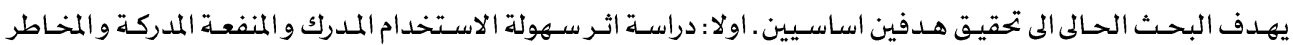
المدركة ومشاركة (اندماج) المستخدم في عملية الشراء product involvement على نيـة اسـتخدام تطبيقات الخـدمات الطبية المجمعة للهاتف. ثانيا : اكتشاف الاسباب التى قد تؤدى مستهلك الخدمات الطبية الى عـدم اسـتخدام هـذا النـوع مـن تطبيقات الهاتف. و قد تم استخدام البحـث الوصفى حيـث تـم جمـع البيانات مـن قطاع عرضى عن طريق استقصـاء 111 مستخدم لتطبيقات الخدمات الطبية المجمعة خلال شهرين(مارس و ابريل 2021) في ثلاث محافظات (القاهرة و الجيزة

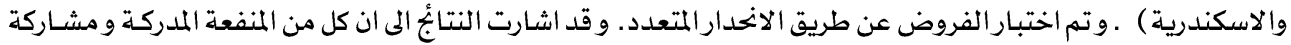

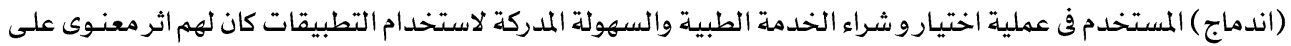

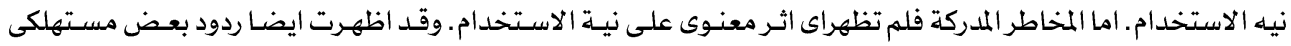
الخدمات الطبية من غيرمستخدمى تطبيقات الهاتف للخدمات الطبية المجمعة الى اكتشاف بعض الاسباب التى تقف وراء دم الاستخدام مستهلك الخدمات الطبية لهذا النوع من التطبيقات. الكلمات الدالة : التسويق عبرالهاتف المحمول، تطبيقات الهاتف،تطبيقات الهاتف للخدمات الطبية.
\end{abstract}

\section{Suggested Citation according to APA Style}

Garas, S. R. (2021). Use Intention of Aggregator Medical Mobile Apps' (M-apps) and Revealing Reasons for Non-Use. Journal of Alexandria University for Administrative Sciences, Faculty of Commerce, Alexandria University 58(5), 171 - 201.

All rights reserved (c) 2021 